\section{Ardentes trópicos: febres e saúde pública no Brasil joanino}

\section{The scorching tropics: fevers and public health in Brazil during the Joanine period, 1808-1821}

\section{Ricardo Cabral de Freitas ${ }^{i}$}

i Pós-doutorando, Programa de Pós-graduação em História das Ciências e da Saúde/Casa de Oswaldo Cruz/Fiocruz. Rio de Janeiro - RJ - Brasil orcid.org/0000-0003-3648-277X rcabral.freitas@gmail.com

Recebido em 15 abr. 2019.

Aprovado em 25 set. 2019
FREITAS, Ricardo Cabral de. Ardentes trópicos: febres e saúde pública no Brasil joanino. História, Ciências, Saúde - Manguinhos, Rio de Janeiro, v.27, n.3, jul.-set. 2020, p.723-740.

Resumo

Com exceção da febre amarela, as febres ainda foram pouco exploradas pela historiografia da saúde brasileira. No século XIX, contudo, sua presença na vida social era quase incontornável, atingindo enormes parcelas da população. Suas vítimas padeciam de uma grande variedade de sintomas em que a identificação e a terapêutica eram objeto de intensos debates nos círculos médicos. A intelectualidade luso-brasileira, atenta tanto aos debates médicos europeus quanto a experiências clínicas, esforçou-se para fornecer respostas na forma de intensa produção impressa; no entanto, as manifestações febris encontradas nos trópicos representavam um desafio extra à sua formação europeia, forçando-a a conjugar experiências adquiridas em partes distintas do Império na constituição de saberes específicos sobre as febres tropicais.

Palavras-chave: febres; medicina tropical; período joanino.

\section{Abstract}

Although fevers (with the exception of yellow fever) have not yet been fully explored by the historiography of Brazilian health, they were almost inevitable in nineteenth-century Brazilian society, affecting huge portions of the population. Their victims suffered from a wide variety of symptoms, and identification and treatment of these symptoms were the object of intense debates in medical circles. The Luso-Brazilian intelligentsia considered European medical debates as well as their own clinical experiences and attempted to provide answers in a flurry of publications. Even so, the manifestations of fever in the tropics presented a challenge that lay beyond their European training, forcing them to combine experiences acquired in different parts of the Empire to comprise specific knowledge on tropical fevers.

Keywords: fevers; tropical medicine; Joanine period (1808-1821). 
A o final da edição de 30 de maio de 1812, a Gazeta do Rio de Janeiro trazia um longo texto, ocupando quase $3 / 4$ de página, noticiando a morte do infante dom Pedro Carlos de Bourbon e Bragança. Como era de se esperar, o tom pesaroso das linhas se devia ao desaparecimento de um membro da Família Real, mas a juventude do falecido, morto aos 25 anos de idade, também contribuía para dar ares ainda mais dramáticos ao ocorrido:

trata-se da morte de um Príncipe na sua mais florente idade: de um Príncipe adornado de virtudes, e qualidades verdadeiramente Reais, e que apenas havia dois anos que se achava unido pelos laços do Himeneu a uma Princesa sumamente respeitável, não só por suas virtudes e raras qualidades, como por ser a Filha Primôgenita de SS.AA. RR. o Príncipe Regente Nosso Senhor, e sua Augusta Esposa, a Princesa Nossa Senhora (Gazeta..., 30 maio 1812, p.4).

A fatal enfermidade que havia deixado viúva dona Maria Teresa, princesa da Beira, era descrita como uma febre lenta nervosa que havia acometido o jovem príncipe quando já se encontrava quase restabelecido de uma "moléstia de que padecera". Aquela não era a primeira perda dolorosa para a Família Real naquele ano. A edição de 29 de janeiro da mesma gazeta havia trazido a notícia da morte do ministro e conselheiro de Estado dom Rodrigo de Sousa Coutinho. Um dos maiores artífices do reformismo ilustrado lusobrasileiro havia sido acometido de uma violenta febre maligna "que lhe terminou a vida em 55 horas" (Gazeta..., 30 maio 1812, p.4). No ano anterior, no fervor da última invasão francesa, Lisboa também fora tomada por uma epidemia de febre contagiosa trazida pela população do interior do reino que se refugiara na antiga corte, afetando também boa parte dos lisboetas e das tropas anglo-lusas que combatiam a Grande Armée comandada pelo general Massena (Gazeta..., 30 maio 1812, p.4).

A febre, como se observa, é o fio que liga esses eventos. O jovem príncipe, o velho conselheiro de Estado, os pobres camponeses do antigo reino, os maltrapilhos combatentes, todos padeceram do mesmo mal que, aparentemente, pouco considerava a posição de suas vítimas na rígida arquitetura social do Antigo Regime português. Por outro lado, há de se considerar também que, se todos foram vitimados pela febre, não se tratava da mesma febre em cada um dos casos. O genro de dom João foi acometido de uma "lenta nervosa"; dom Rodrigo, por sua vez, fora levado por uma "maligna"; enquanto Lisboa foi tomada pela "epidêmica". Cada uma dessas classificações tem sua própria história, e a maneira como aparecem nos jornais é resultado de uma longa e controversa tradição de estudos sobre um tema que animou debates médicos desde a Antiguidade (Hamlin, 2014; Bynum,1981).

Neste artigo, contudo, nos concentraremos menos na tarefa de restabelecer essa arqueologia do que em apresentar as febres como o fenômeno de presença praticamente incontornável na vida dos indivíduos do mundo luso-brasileiro ainda no alvorecer do século XIX. Apesar de considerável literatura já ter se debruçado sobre esse tema no contexto europeu (Bynum, 1981; Hamlin, 2014), pouco ainda foi feito na historiografia brasileira, que acabou por dispensar mais atenção à febre amarela, sobretudo após a epidemia de 1849 (Chalhoub, 2004; Benchimol, 1999; Franco, 1969). Embora seu protagonismo tenha sido inegável, sobretudo por conta das crescentes apreensões geradas 
pelas epidemias nos portos e cidades luso-brasileiras a partir das primeiras décadas do século XIX, cabe observar que a febre amarela consistia em mais uma das manifestações febris que ceifavam vidas por aqui há longo tempo. Nesse sentido, como tem observado historiografia recente, os discursos oitocentistas sobre a febre amarela não podem ser propriamente analisados sem que se faça observância às diversas concepções de febre em disputa na época. ${ }^{1}$

Assim, nosso percurso se dará em três partes, cada uma delas referente a um aspecto da presença das febres no ambiente social luso-brasileiro, que têm se revelado frentes promissoras de pesquisa, são elas: (1) a forte presença das febres nas questões de saúde pública em Portugal e no Brasil por meio de suas referências nos jornais, em correspondências pessoais e políticas públicas de saúde; (2) a existência de uma tradição lusitana de estudos acerca das febres que, sobretudo na segunda metade do século XVIII, mostrou-se cada vez mais afinada tanto com os debates médicos europeus sobre o tema quanto com o processo de afirmação de políticas públicas de saúde em Portugal e nas colônias; e, por fim, (3) a conformação de conhecimentos específicos a respeito das febres no Brasil durante o período joanino, em grande parte devedora das experiências prévias de médicos como funcionários imperiais em domínios portugueses.

Antes de prosseguirmos, cabe observar algumas características fundamentais do nosso objeto, portanto indispensáveis ao nosso percurso. Para o leitor do século XXI, a apresentação das febres nas notícias de jornal mencionadas pode causar certo estranhamento. Afinal, o que significava morrer de febre? Com raras exceções, como a amarela ou a escarlate, as febres são para nós hoje sintoma de algum processo patológico em curso, e não doenças em si. O aumento da temperatura corporal, geralmente acima dos $37^{\circ} \mathrm{C}$, remete-nos a uma reação imunológica à presença de algum agente patogênico no organismo, ao qual se associa um diagnóstico específico, previsto no repertório médico de nossos dias. Não era assim para nossos antepassados. Desde a antiguidade até o estabelecimento da microbiologia no final do século XIX, as febres correspondiam a um conjunto amplo e difuso de manifestações patológicas e podiam ser entendidas tanto como sintoma de alguma enfermidade quanto como enfermidade em si. O calor, hoje característica definidora da febre e medido com precisão pelo termômetro, não passava de sintoma marginal e de menor importância para muitos praticantes da medicina. Esses estavam mais atentos ao pulso, ao vigor observado no paciente, às dores que relatavam sentir, às secreções que expeliam, associados à sua história de vida, hábitos alimentares, atividades diárias e a uma intrincada série de outros fatores.

Diante desse espectro alargado de manifestações atribuídas às febres, os sintomas considerados relevantes pelo praticante da medicina variavam enormemente na definição de diagnósticos e tratamentos. Entre os séculos XVIII e XIX, isso se traduziu numa verdadeira batalha entre tradições nosográficas que, ao atribuir naturezas distintas às febres, originaram uma profusão de classificações e modelos terapêuticos que digladiaram entre si (Hamlin, 2014). Como veremos, a plasticidade do tema, associada à sua presença marcante na vida social, foi o combustível definitivo para sua longa permanência na agenda médica. 


\section{Febres e vida social}

Menos de um ano após a transferência da corte para o Brasil, a Gazeta do Rio de Janeiro noticiou a morte do conde da Ponte, governador da Bahia, causada por uma "febre contínua" acompanhada de uma "dor de lado" e "fastio". O conde havia sido acompanhado pelo médico José Avellino Barbosa, que "o pôs em uma rigorosa dieta de água morna, e caramelo, e muito uso de Láudano". Com a persistência dos sintomas por vinte dias, o médico aplicoulhe um "vesicatório" para diminuir a dor. Sem obter sucesso, Barbosa acabaria substituído por uma junta composta pelos médicos França, Manoel Luiz, Alvarenga e o cirurgião Barata. Em conjunto, "assentaram pôr-lhe umas papas sobre o lugar da dor, a ver se se descobria a matéria". Mais uma vez, os esforços se mostraram infrutíferos, e o conde faleceu entre $10 \mathrm{~h}$ e 11h da manhã do dia 24 de maio de 1809 (Gazeta..., 9 jul. 1809, p.3).

Pode-se imaginar o efeito que mortes como essa tinham entre aqueles que aportavam na colônia alçada à capital do Império português naqueles tempos. Não por acaso, a Coroa implementou um amplo programa de reformas visando garantir a salubridade dos espaços urbanos locais, com maior ênfase no Rio de Janeiro, como veremos. No entanto, cabe adiantar que, mesmo na nova capital, os esforços não surtiram efeito imediato, e outras personalidades ilustres da corte foram levadas pelas febres nos anos seguintes.

No ano que se seguiu às mortes de dom Rodrigo de Sousa Coutinho e dom Pedro Carlos de Bragança, foi a vez de Thomé José de Sousa Coutinho Castello Branco e Menezes, o primeiro marquês de Borba. De acordo com o relato, fora vitimado de uma "violenta febre", não especificada, mas que esvaiu suas energias em 18 dias, nos quais "suportou a enfermidade com uma resignação verdadeiramente cristã" (Gazeta..., 23 out. 1813, p.4). Meses depois, a febre lenta nervosa faria mais uma vítima entre os ministros de dom João. O conde de Galvêas, secretário de Estado dos Negócios da Marinha e Domínios Ultramarinos, faleceu em 18 de janeiro de 1814, aos 56 anos de idade (Gazeta..., 22 jan. 1814, p.3). Por fim, o ano de 1817 levou Antônio de Araújo de Azevedo, o conde da Barca, aos 65 anos de idade, também vitimado por uma febre nervosa (Gazeta..., 28 jun. 1817, p.2). Sua morte veio aproximadamente um ano após ter auxiliado dom João no processo de elevação do Brasil a Reino Unido, contabilizando o terceiro ministro do príncipe regente perdido para as febres.

Durante esses anos, habitava na capital o bibliotecário Luiz Joaquim dos Santos Marrocos, encarregado por dom João da organização e conservação dos manuscritos da Coroa após servir como ajudante nas bibliotecas reais em Lisboa. Sua proximidade com o centro do poder possibilitou que estivesse a par de assuntos privados da corte, não raro relatados em suas cartas aos seus familiares em Portugal. Em 1813, por exemplo, comentou em carta ao seu pai que o infante dom Miguel "achava-se doente com muita febre" (Marrocos, 1939, p.143). Segundo a sua versão, a morte do conde de Galvêas em 1814 teria sido causada pelo desgosto de não conseguir o título de marquês (Marrocos, 1939, p.180). Em 1816, relatou a seu pai em detalhes a degradação do estado de saúde de dona Maria I, o que a levou à morte no mesmo ano (Marrocos, 1939, p.228, 256, 258).

Contudo, o que chama mais atenção em seus relatos é a presença frequente das febres em sua vida privada. Mesmo ocupando cargo de prestígio na corte, Marrocos e sua família eram vulneráveis às enfermidades e epidemias que grassavam regularmente na cidade. Em 
carta de março de 1814, mostrou-se temeroso com a estiagem atípica no Rio de Janeiro para aquela época do ano: "Tem havido grandes moléstias e mortes súbitas, e muitas febres". Sua apreensão direcionava-se especialmente a "uma certa moléstia de garganta e narizes" que de tão violenta vitimava fatalmente os enfermos em menos de dez dias, sobretudo crianças (Marrocos, 1939, p.187). Dois meses depois, relatou a seu pai a doença de seu filho, uma febre contínua "que lhe chamam intermitente, e que reina agora muito; há 3 dias não dá acordo de si, de sorte que se lhe deitam os caldos e remédios com violência pela boca abaixo; e eu desconfio que haja ali proximidade de bexigas, por que ainda não as teve" (Marrocos, 1939, p.196). Em setembro de 1816, queixou-se de que "quase todos desta Casa temos padecido mais ou menos nesta estação de epidemias, que tem grassado por toda a Cidade". Marrocos (1939, p.286-287) afirmava ter adoecido não muito depois de sua esposa e permaneceu de cama por 17 dias "em razão das febres que continuaram por aquele tempo". No final daquele ano, o bibliotecário adoeceu novamente vitimado por uma "febre biliosa contínua". A enfermidade foi agravada por uma hemiplegia que quase o fez "passar à eternidade" e que lhe deixou surdo e parcialmente cego no lado esquerdo: "Havia mais de um mês que já curtia de pé uma febre, que era contínua com fastio de morte, mas agravando-se esta pouco a pouco, cheguei à margem da sepultura" (Marrocos, 1939, p.290). O tratamento, como relatou em carta posterior, não foi menos duro:

Retirei-me por duas vezes da Cidade para o Campo, onde mandei alugar uma Chácara para tomar ares, e fortificar-me da excessiva debilidade, a que fiquei reduzido ... além dos banhos de mar, aplicarão-se-me sanguessugas no lugar das hemorroidas por duas vezes, e agora torno aos banhos e choques elétricos ao ouvido (Marrocos, 1939, p.297).

No verão de 1818, a família foi mais uma vez castigada pelas febres. A casa do bibliotecário, segundo descreve, teria "figurado um Hospital com febres catarrais e sarampo". Dessa vez, Marrocos (1939, p.347) foi o primeiro a se contaminar, mas a doença foi mais dura com sua filha, que "esteve quase morrendo com três repetições da catarral, que a reduziu a abatimento e magreza considerável". Felizmente, todos se curaram, mas às custas de exaustivos trabalhos do bibliotecário e de sua esposa.

Mesmo se tratando da família de um funcionário de prestígio da Coroa, os relatos de Marrocos nos ajudam a vislumbrar um pouco do universo das experiências da população com as febres em âmbito familiar, e para além das figuras de destaque que apareciam nos jornais. Certamente, se sua família era tão vulnerável quanto aparentava ser às oscilações das epidemias na capital, é certo que a situação se agravava sobremaneira entre os estratos menos favorecidos da população local. Entre esses, as fontes ainda são escassas e as poucas exceções parecem ser justamente aqueles ainda mais desprivilegiados, cuja própria humanidade era eclipsada pelo estatuto de mercadoria, como a negra Maria Conga, achada enferma de febre na chácara do conselheiro físico-mor do Reino e conduzida à Santa Casa de Misericórdia. Lá permaneceu retida pelo menos seis meses junto a outros cativos aguardando que se achasse "a quem pertençam os referidos pretos" (Aviso, 29 jan. 1814, p.4).

Entre as autoridades, as febres despertavam maiores apreensões quando vindas na forma de epidemias que poderiam inclusive atrapalhar o próprio funcionamento da máquina administrativa. Em outubro de 1816, o cirurgião-mor de Minas Gerais, João Rodrigues da 
Cruz, justificou o atraso de sua chegada ao Rio de Janeiro ao cirurgião da Real Câmara, Florêncio dos Santos Franco, por sofrer ele mesmo de uma febre epidêmica que grassava em São João del Rey. A enfermidade, que teria feito diversas vítimas na localidade, deixou o cirurgião acamado durante três semanas, tonando impossível o cumprimento de suas diligências (Cruz, 26 out. 1816). As febres dos funcionários reais também poderiam gerar despesas extras ao erário. Em junho de 1817, o oficial de registro da secretaria do tribunal do Conselho Ultramarino, Camillo Alexandre de Azevedo e Costa, enviou requerimento a dom João relatando ter sofrido de uma febre maligna no ano anterior que o "obrigou a fazer uso de remédios maiores". Buscava assim obter algum auxílio da Coroa, visto que "em tais circunstâncias V. Mag. costuma mandar dar uma ajuda de custo aos Oficiais que bem servirem" (Costa, 3 jun. 1817).

Contudo, em se tratando de um império de forte vocação portuária, não há dúvidas de que as febres trazidas por embarcações era um mal ainda mais temido. Um artigo publicado em 1812 no Correio Brasiliense destinava duras críticas à administração da Repartição da Saúde no porto de Lisboa, que supostamente continuava a aplicar medidas inadequadas para prevenir a propagação de epidemias na cidade mesmo após a expedição de um alvará real exigindo profunda fiscalização do serviço. Em determinado trecho, criticava a quarentena requerida dos navios que chegavam do Rio de Janeiro após uma epidemia de febre contagiosa na cidade: "como se 4 a 6 dias fosse mais prova de não existir o contágio, do que 80 ou 100 dias, que se tem decorrido naquela longa viagem" (Miscelânea, 1812, p.687).

Durante as guerras napoleônicas, intensificou-se a vigilância dos portos por conta dos surtos epidêmicos na Europa. Da nova capital, acompanhava-se pela Gazeta do Rio de Janeiro as notícias de epidemias de febre em áreas de conflito. Em 1811, o jornal demonstrou particular preocupação com as notícias que chegavam de Gibraltar a respeito da eclosão de um novo surto de febre em Cartagena, em plena Guerra Peninsular. As notícias destacavam a violência da epidemia e as medidas preventivas tomadas pela Coroa portuguesa:

São medonhas as notícias que ontem recebemos de Cartagena sobre o progresso da febre naquela infeliz Cidade. Morrem mais de 60 pessoas ao dia, e como se tem escapado muitos fugitivos por várias partes da costa, julgou-se prudente cortar desde já toda a comunicação com Espanha por mar e por terra. Ontem morreram 11 pessoas a bordo dos transportes que se acham nesta baía, e estão 40 perigosamente enfermas (Gazeta..., 2 fev. 1811, p.1).

Mais adiante, afirmava-se tratar de uma febre epidêmica, que também havia afetado Cádiz, o porto de Santa Maria e a cidade de Chiclana, chegando até as tropas francesas (Gazeta..., 2 fev. 1811, p.1).

Apesar disso, essa epidemia que afetou Lisboa entre 1810 e 1811 foi considerada de menor malignidade:

Os habitantes das terras invadidas pelo inimigo, além de muitas aflições morais, sofreram e sofrem ainda privações das coisas mais necessárias à vida; os contratadores dos diversos gêneros, pela carestia em que puseram tudo, tornaram inda mais difícil a subsistência. Daqui principalmente é que tem nascido muitas febres; assim como de se terem amontoado muitas pessoas em pequenas casas baixas a úmidas etc. Porém estas febres são de sua natureza mui pouco malignas; no Hospital Real de S. José, e 
nos Hospitais militares (onde são contudo muito menos) se tem curado, e curam em mui grande proporção, e segundo as comunicações que temos de muitos Médicos, e certamente os de Portugal são dos mais instruídos da Europa; nas casas particulares curam-se quase todos os doentes, que têm meios de se tratarem: à exceção de casos particulares que não alteram de modo algum a regra geral (Gazeta..., 25 maio 1811, p.3).

Embora nossa abordagem aqui se restrinja ao período joanino, é evidente que as febres já representavam riscos à saúde pública muito antes da transferência da Corte para o Brasil. Como veremos na próxima seção, as febres já estavam no horizonte da intelectualidade luso-brasileira havia tempos. A partir dos debates europeus a respeito do tema, parte significativa dos súditos da Coroa debruçou-se sobre as febres sem, no entanto, deixar de levar em consideração a diversidade climática e social do Império.

\section{Os estudos luso-brasileiros sobre as febres}

A segunda metade do século XVIII foi marcada por uma crescente aproximação entre os saberes médicos, sobretudo os de origem acadêmica, e a agenda da administração pública dos Estados nacionais europeus. Em termos epistemológicos, esse processo teve forte contribuição da consolidação das matrizes de pensamento vitalistas que deram lastro a uma cosmologia médica cada vez mais calcada na interdependência e na indissociabilidade entre os aspectos físicos e morais dos indivíduos (Rey, 2014; Duchesneau, 2012; Williams, 1994). Em termos práticos, isso significou que a saúde do corpo passou a ser cada vez mais associada à saúde do espírito, e vice-versa.

Os efeitos sociais mais visíveis se deram no sentido de uma ofensiva crescente do saber médico sobre as condutas comportamentais, tanto individuais quanto coletivas. Assim, a ordem social passava a depender também do bom equilíbrio físico e moral dos cidadãos. A administração pública, por sua vez, enfrentava novos desafios ao manejar um contingente populacional urbano crescente e cada vez mais complexo. As massas de desvalidos submetidos a condições de higiene precárias eram vistas como ameaças à ordem social e sanitária, de maneira que o projeto médico de tutelar o conjunto da sociedade serviu bem aos anseios estatais. Os resultados foram muitos, e vão desde o surgimento de novos modelos de regulação do comércio e dos espaços públicos até tentativas - frequentemente frustradas, diga-se de passagem - de institucionalizar as profissões médicas e excluir da arena pública os saberes de cura tradicionais (Quinlan, 2007).

No caso português, cabe salientar dois dos efeitos mais evidentes desse processo. $\mathrm{O}$ primeiro foi o fortalecimento da higiene como disciplina médica e parte indispensável do currículo da Faculdade de Medicina de Coimbra a partir da reforma de 1772 (Freitas, 2017). O segundo foi a profusão de obras e tratados de medicina produzidos no contexto do reformismo ilustrado que, longe de se deter aos aspectos econômicos, também procurou reformar as bases culturais da sociedade portuguesa, em parte pela criação de indivíduos física e moralmente saudáveis e comprometidos com a manutenção ordeira do tecido social (Barreiros, 2014).

Entre essas obras que circularam na América Portuguesa, nota-se que boa parte reservava um número significativo de páginas às febres. Se considerarmos que essa literatura se voltava 
não apenas para os médicos, mas também para indivíduos e famílias leigas em medicina, pode-se entender a presença das febres como pista segura da sua relevância para os dramas pessoais da maior parte da população. Assim nos indica Jozé Manoel Chaves (1746-1811), que definiu a febre como "a mais poderosa serpente que destrói a natureza humana" (Chaves, 1790, p.8). Sua obra, Febriologia acomodada, tinha como objetivo justamente ser uma referência ao público português em meio à "multidão quase imensa de livros, com que os Mestres da França, da Alemanha, da Itália, e da Inglaterra têm inundado a nossa Europa". Reivindica assim uma medicina voltada para as particularidades locais das manifestações patológicas, calcada, acima de tudo, na experiência do prático em sua região de atuação. Por isso, afirma que Portugal poderia ter conhecimento muito mais amplo das patologias comuns no Reino se os médicos que ocupavam os "Partidos das Câmeras" fossem obrigados a relatar suas observações à administração central:

Há países neste Reino onde as febres intermitentes; e malignas fazem quase todos os anos terríveis estragos, como são por exemplo nos campos de Chaves, Golegam, e Coimbra. Um Médico que de novo entra em qualquer país não será tão venturoso nas suas curas, como aquele que já lhe conhece os furores com que ali se representam, e as suas qualidades. ... Deve o homem, segundo Cícero, ser útil à pátria non solum nobis nati sumus (Chaves, 1790, p.9).

A obra se baseia nos conhecimentos adquiridos pelo autor como médico na vila de Condeixa. A inspiração eclética iluminista, militante da observação "direta" dos fenômenos, associa-se ao discurso da promoção do bem público como motivações primordiais da publicação, que tinha como pretensão atingir um público mais amplo que o dos profissionais da medicina:

Isto nada mais é que uma confirmação de algumas doutrinas práticas que estabeleceram aqueles Médicos que atentamente olharam para a natureza febricitante, e por isso me cinjo à Medicina Eclética.

O Sábio, e o plebeu poderão abraçá-las, e o Censor amigo da novidade abandoná-las, porque cada qual abunda no seu pensar. ... Evitarei, quanto puder os termos facultativos e expressões pomposas, para que melhor me explique, e bem me percebam; pois só estas podem ter lugar para com as pessoas eruditas em Matérias Medicinais (Chaves, 1790, p.11).

Manuel Henriques de Paiva foi outro personagem de destaque nesse contexto. Lente da Faculdade de Filosofia da Universidade de Coimbra, entre outros cargos de prestígio (Silva, 1858, p.12-13), foi banido para o Brasil em 1808 por conta de suas supostas simpatias pela Revolução Francesa. Porém, não cessou sua produção durante o período de isolamento político. Em 1813, publicou na Bahia Da febre e sua curação em geral, uma tradução da obra de Gottfried Christian Reich (1769-1848). Paiva conta que o método de Reich para "sanear facilmente todas as espécies de febre" havia tido ampla aceitação na corte da Prússia, sendo referendada pelo Real Colégio de Medicina e pelo próprio rei. O método milagroso do médico germânico baseava-se no uso de ácidos minerais para tratar as febres e poderia soar "escura, e extravagante àqueles, que ignoram a Química moderna" (Paiva, 1813). A versão portuguesa saiu 12 anos após a original e era derivada da edição francesa, publicada nas 
memórias da Société Médicale d'Émulation de Paris. Como era comum em suas traduções, Paiva não se restringe em verter a obra de sua língua original e acresce anotações próprias, em geral voltadas para o contexto luso-brasileiro. Diante da rejeição de Reich à utilização do ácido nítrico por conta de suas características corrosivas, por exemplo, escreve uma nota demonstrando que essas propriedades poderiam ser mitigadas com diluição em água e açúcar, e que sua experiência mostrava que o uso da substância poderia ser "enérgico e proveitoso no clima quente e úmido da Bahia" (Paiva, 1813, p.71, 118).

Por outro lado, fica claro que a simpatia de Paiva pelos ácidos minerais de Reich ia muito além de uma contribuição desinteressada para o combate às febres. A publicação era também uma resposta à sua situação política:

era minha tenção que esta memória saísse à luz, acompanhada de um sumário cronológico do uso, que os médicos têm feito dos ácidos minerais, quer misturados com água, quer com o álcool, e com as substâncias aromáticas, nas diversas enfermidades do corpo humano; mas, além de me tolher aquela minha tenção o quebrantamento das forças por achaques continuados, faltam-me os livros necessários, que, em razão das minhas adversas circunstâncias, não posso haver. Virá tempo em que satisfazer possa os meus ardentes desejos, e então darei mais uma prova de que a minha terra amei e a minha gente (Paiva, 1813, p.10).

Privado de seus títulos e afastado da corte, Paiva apostou na introdução de um método inovador para combater um flagelo que atacava grande parte da população colonial. Caso surtisse efeito, era possível que o prestígio adquirido fosse suficiente para catapultá-lo de volta às posições privilegiadas de outrora, o que conseguiria só três anos depois, com um perdão régio de 1816 (Filgueiras, 1992).

Outras de suas traduções célebres também dedicavam espaço considerável às febres. $\mathrm{O}$ Aviso ao povo acerca de sua saúde, de Samuel August Tissot (1786), dedicou quatro dos 22 capítulos do primeiro volume às febres "inflamatórias", "pútridas" e "malignas". Ao longo do texto, são descritas as causas e sintomas mais visíveis de cada uma das febres e, por fim, são indicados os meios mais adequados de tratá-las. Por também se tratar de obra destinada a um público não treinado na medicina acadêmica, há grande cuidado em descrever a marcha da doença e as medidas aconselhadas para cada tipo de manifestação esperada, o que também se verifica na Medicina doméstica de William Buchan (1788), traduzida por Paiva dois anos depois.

Mesmo no continente europeu, obras com essas características eram altamente desejáveis para uma medicina ávida por alargar o alcance de seu discurso diante de uma população cujo acesso a médicos era escasso e custoso. Sua força advinha justamente da capacidade de fazer referência a um conjunto de experiências mais ou menos partilhadas por indivíduos comuns e por praticantes da arte médica em diferentes contextos. Não há dúvida de que esses fatores não passaram despercebidos para personagens como Paiva, que não por acaso escolheu traduzir escritos que já gozavam de sucesso editorial e estavam intimamente conectados ao universo de ideias médicas do Velho Mundo. No entanto, havia outras linhas de força na produção de obras médicas no período. Para além dos escritos que buscavam uma aplicabilidade mais generalizada, muitos sábios dedicaram suas penas a compreender as particularidades das manifestações patológicas em climas e geografias específicos. 
Essa tendência foi imperativa sobretudo em contextos imperiais como o português e o britânico, nos quais médicos europeus eram frequentemente desafiados a praticar sua arte em localidades distantes do clima temperado. As febres ofereceram desafio particular nesses casos.

\section{Medicina atlântica e as febres nos trópicos}

A construção dos impérios ultramarinos a partir do final do século XV incrementou de maneira até então inédita as dinâmicas de circulação de pessoas, bens e informações entre o continente europeu e Ásia, África e américas. Ao mesmo tempo que permitiram o estabelecimento de complexas empresas coloniais, essas redes também expuseram os conhecimentos europeus a um contato renovado com culturas, climas e geografias diversas (Boxer, 2002). Não raro, o domínio das particularidades desses novos ambientes tornava-se indispensável para a sobrevivência daqueles que lá se estabeleciam e também para a própria manutenção das relações coloniais. Tais imperativos, como destaca Londa Schiebinger (2017), contribuíram para fazer dos ambientes coloniais verdadeiros complexos médicos. Nesses espaços floresceram culturas experimentais nutridas pelo intercâmbio de plantas, medicamentos, pessoas e animais, possibilitando o entrecruzamento de tradições de cura e o incremento do próprio repertório curativo da medicina acadêmica europeia. Nesse sentido, parte da historiografia de língua inglesa tem apontado que a expansão colonial britânica desempenhou papel fundamental na literatura sobre as febres, sobretudo a partir dos Setecentos. Algumas das obras mais prestigiadas na virada do século surgiram da experiência de médicos em missões militares em domínios coloniais, como James Lind (1716-1794), Sir John Pringle (1707-1782) e Robert Robertson (1742-1829). Mesmo William Cullen (1710-1790), referência de destaque para o tratamento de febres entre os luso-brasileiros, passou vários anos em serviço na Jamaica antes de escrever sua famosa First lines of the practice of physics (1784) (Hamlin, 2014; Bynum, 1981).

Como se sabe, o Império Português também se constituiu a partir do estabelecimento de amplas redes de circulação de bens, mercadorias, indivíduos e saberes (Boxer, 2002; Russel-Wood, 2016), e embora as missões militares não pareçam ter desempenhado papel tão decisivo quanto no contexto britânico, as produções sobre as febres também se valeram das experiências do além-mar. Em trabalho recente, Hugh Cagle (2018, p.12-13) aponta a contribuição dos estudos sobre as febres no Atlântico lusitano no estabelecimento da noção de "trópicos" na mentalidade europeia. Como destaca, um relativamente amplo conjunto de praticantes de medicina portugueses politicamente conectados e de formação universitária contribuiu, a partir do século XVII, para tornar evidentes as semelhanças climáticas e nosológicas de áreas intertropicais afastadas entre si, mas igualmente submetidas ao domínio lusitano. Ao analisar a trajetória de Aleixo de Abreu, médico que serviu à Coroa em Angola e Pernambuco no século XVII e autor do Tratado de las siete enfermidades, Cagle mostra como as manifestações febris encontradas em regiões tropicais tornaram-se tema de alta relevância para a administração colonial, motivando seus representantes no além-mar a explorar terapias inovadoras que conjugavam saberes curativos locais, posteriormente remetidos a Lisboa (Cagle, 2018, p.208-233). 
Em geral, a relevância dessas obras para a administração colonial era diretamente proporcional ao seu potencial para elucidar questões de saúde e salubridade locais que poderiam ameaçar o bom curso das atividades produtivas. Não foi por acaso que, em pleno Pernambuco açucareiro, João Ferreira da Rosa publicou o Tratado único da constituição pestilencial de Pernambuco $(1694$, p.2) a respeito de uma febre que havia grassado no local anos antes:

há sete anos assiste-se uma grave doença, a qual nunca jamais nele [Pernambuco] se viu (antes se constituía um clima tão admirável, que parecia sempre na igualdade das qualidades uma suavíssima Primavera, tão isento das doenças cruéis, que em nenhum dos anos de nossas memórias as padeceu).

A grave doença a que se refere é definida como uma febre pestilente, ${ }^{2}$ "a mais cruel doença, que tem o mundo: a qual por sua má qualidade oculta inimiga do coração, tem feito mais estrago, do que outras contagiosas" (Rosa, 1694, p.3). Rosa destaca a alta mortalidade testemunhada nos primeiros momentos da epidemia em Pernambuco que "quase o deixou deserto". Segundo descreve, o calvário das vítimas costumava durar em torno de seis a nove dias, embora houvesse casos em que os doentes "não duraram mais de 24 horas". O número de mortos teria chegado a pouco mais de duas mil pessoas, mas alguns relatos apontavam número ainda mais elevado, trazendo à tona, inclusive, alguns dos mais profundos temores das elites coloniais seiscentistas: "chegou a ponto de não haver homens para acompanhar o Santíssimo Sacramento; e se presumiu que o Gentio queria senhorear; o que milagrosamente se preveniu" (Rosa, 1694, p.5).

O caráter contagioso da doença seria influenciado pela "pestilencial qualidade" nas igrejas, onde se abriam a "cada hora tão incautamente covas, que além de se não fazerem fundas, se enterravam na mesma parte, ou covinha cinco, e seis corpos" (Rosa, 1694, p.4). Mas essas causas não seriam mais do que causas auxiliares. Para Rosa, uma doença "mais geral" exigiria também uma causa "comum e geral" que estaria nas particularidades do clima de Pernambuco. Calcado numa apropriação do corpus hipocrático permeada de elementos aristotélicos e mágico-astrológicos, aponta a qualidade do ar de Recife como resultado direto da moralidade de seus habitantes e sentencia: "E irada a Justiça Divina de nossa contumácia, prosseguirá este contágio, enquanto se não reformarem nossos péssimos costumes" (Rosa, 1694, p.13). Por fim, os eclipses também teriam o poder preponderante, cujos efeitos nocivos eram impulsionados pelos "vapores da carne podre" já existentes no ar.

Publicada 17 anos antes, Queixas repetidas em ecos dos arrecifes de Pernambuco (1677) foi outra obra de destaque no período. Foi escrita por Simão Pinheiro Morão, médico natural de Covilhã, que chegou ao Brasil provavelmente em 1671 após trajetória conturbada com o Santo Ofício em Portugal. Logo no início do texto, relata sua frustração com a ignorância da população local, supostamente não conhecedora dos princípios básicos da boa medicina e sujeita a abusos de toda sorte no trato das artes de curar. Da lista de 12 queixas descritas pelo médico, o desconhecimento do clima aparece em primeiro lugar. Segundo afirma, ao clima quente e úmido encontrado em "toda a América muito particular o de Pernambuco", os habitantes atribuíam "qualidades diversas da que possuía não o julgando como deviam", crítica destinada não apenas aos habitantes em geral, mas particularmente aos cirurgiões 
que atuavam na região (Morão, 1692, p.6). O autor assume então uma postura pedagógica e dedica-se a apontar meios de coibir ou extinguir os abusos amplamente cometidos no local. Nos três capítulos dedicados às febres, analisa-as como resultado de uma perturbação dos humores que constituem o corpo humano, sendo mais comuns aquelas causadas por excesso de cólera (Morão, 1692, p.31). Descreve-as de maneira minuciosa, de forma que pudessem ser distinguidas umas das outras com clareza, e prescreve as sangrias como a melhor terapia, alertando sobre os abusos dessa prática cometidos em Pernambuco.

Durante o período do reformismo ilustrado, o caráter utilitário de parte da produção médica lusitana atingiu seu auge, contudo, o caráter local das enfermidades passou a ter mais centralidade. Os Ensaios sobre algumas enfermidades de Angola (1799) são resultado do período em que José Pinto de Azeredo permaneceu em Luanda como físico-mor, cargo para o qual foi nomeado em 1789. No primeiro parágrafo, já se pode verificar mudanças de postura significativas em relação às obras de Rosa e Morão:

As febres de Angola são da mesma natureza daquelas que se observam nos outros países situados na zona tórrida. Eu as observei no Rio de Janeiro, na Bahia, e em Pernambuco, bem que nestes dois últimos são muito menos frequentes. Os paroxismos, as crises, os progressos e os sintomas são igualmente os mesmos, e, por isso, o método de cura destas, que passo a descrever, deve ser da mesma sorte aplicado nas febres de outros climas. Eu o principiei a pôr em prática na cidade do Rio de Janeiro, e o feliz êxito que então obtive me convenceu de o continuar em Angola, onde achei um curativo totalmente oposto (Azeredo, 2013, p.19).

Azeredo propõe uma abordagem das febres voltada especificamente para climas "tórridos" ou tropicais. Embora isso não fosse inédito nos círculos médicos europeus da época, tratava-se de uma abordagem ainda pouco comum no Império Português. As obras de Rosa e Morão não tinham objetivo de produzir uma abordagem original das febres em climas quentes, mas de indicar os dispositivos que haviam possibilitado a manifestação na colônia de febres já conhecidas na Europa. Isso fica bem claro no tom professoral de Morão, que chegou a Pernambuco disposto a revelar para a população local, supostamente inculta, a real natureza das doenças de que sofriam. Azeredo, por sua vez, parte de uma cosmologia médica renovada, na qual os astros e a ira divina com os pecados mundanos já não marcavam tanta presença. Mesmo que se apoie na literatura europeia sobre as febres, e até mesmo sobre as febres tropicais, procura produzir uma abordagem original e não poupa críticas a autores consagrados entre seus pares europeus, como o próprio William Cullen:

Os Médicos que observam cuidadosamente, e às cegas, as doutrinas de Hipócrates, ainda hoje esperam nas febres pelos dias críticos. Alguns autores do presente século fazendo-se uns meros copiadores das doutrinas antigas, deixaram de refletir sobre elas, e fizeram passar para os nossos dias o inviolável respeito das suas opiniões. O mesmo Cullen, meu sábio Mestre, sendo um homem livre e eclético, caiu no mesmo erro dos dias críticos. Cullen sustenta a doutrina hipocrática de semelhantes dias, trazendo por prova os movimentos periódicos que se observam continuamente na economia animal, tanto no estado de saúde, como no de moléstia (Azeredo, 2013, p.33).

Para Azeredo (2013, p.33-34; destaque no original), tais movimentos não teriam origem na "força medicatriz da natureza', descoberta por Stahl", como insinuava Cullen, mas sim 
em causas físicas de natureza distinta, o que para ele desterraria completamente essa parte da doutrina hipocrática:

Eu observo febres terminarem tanto nos dias chamados críticos, como nos dias não críticos. A opinião de Cullen é pouco provável. A invenção dos dias críticos faz com que o Professor, esperando pela crise, deixe de continuar com os remédios necessários naquela mesma ocasião em que eles mais sejam precisos, e em que talvez decidam a vida do enfermo.

Outro ponto a ser destacado na obra de Azeredo é que tanto sua postura crítica em relação à literatura europeia quanto seus conhecimentos sobre as febres em Angola baseiamse, como ele mesmo afirma, em suas experiências no Rio de Janeiro e em Pernambuco. Tal aspecto diz respeito a uma horizontalidade da circulação de conhecimentos dentro do próprio Império Português ainda pouco abordada pela historiografia. Sua atuação na América Portuguesa foi determinante na criação de métodos originais de combate às febres que agora se imiscuíam a novos conhecimentos adquiridos no continente africano.

Esse aspecto também pode ser verificado em produções do período joanino, quando as preocupações com as particularidades do clima, geografia, fauna e flora do Brasil tomaram novo impulso. A partir da transferência da Corte para o Rio de Janeiro em 1808, tornou-se imperativo intervir nas péssimas condições de higiene da cidade e combater as moléstias que ameaçavam a saúde de seus habitantes e visitantes, fazendo com que o tema da salubridade ganhasse importância renovada na agenda da administração local. Afinal, não se tratava somente de esforço civilizatório, era preciso fazer da cidade um espaço produtivo, que gerasse lucros econômicos, sociais e políticos para um governo debilitado politicamente e com a soberania em risco diante do complicado quadro político da Europa napoleônica (Villalta, 2016; Silva, 2013).

A Coroa tornou-se então incentivadora direta de trabalhos científicos dedicados a compreender as especificidades sanitárias da nova capital. Um dos marcos desse período foram as Reflexões sobre alguns dos meios propostos por mais conducentes para melhorar o clima da cidade do do Rio de Janeiro, de Manuel Vieira da Silva, médico da Câmara Real. Publicado ainda em 1808, acabou adquirindo notoriedade, em parte por ser um dos primeiros produtos da recém-inaugurada Impressão Régia no Brasil. Feito sob encomenda do príncipe regente, procurava descrever as características do relevo, das temperaturas e da circulação de ar e seus efeitos sobre a saúde dos habitantes do Rio de Janeiro (A saúde pública..., 2008). Boa parte dos autores que se dedicaram a produções dessa natureza fazia parte da intelectualidade atraída para o Brasil na esteira da transferência da corte. Com o objetivo de se estabelecerem num contexto social e político relativamente novo, colocavam seu intelecto a serviço de temas relevantes aos olhos da administração da capital, visando obter ganhos políticos e profissionais. Diante das perdas que a corte havia tido em poucos anos para as febres, não estranha que elas tenham tido seu lugar nas investigações levadas a cabo por essa intelectualidade.

Francisco de Mello Franco é um exemplo emblemático desse perfil intelectual. Escreveu em 1821 o Ensaio sobre as febres do Rio de Janeiro, dedicado ao estudo das particularidades das febres encontradas na capital em comparação com os tipos mais comuns na Europa. 
Conforme já mostramos em outro trabalho, era natural de Paracatu, Minas Gerais, e havia retornado ao Brasil poucos anos antes, quando pôs termo à sua bem-sucedida trajetória em Lisboa para acompanhar a arquiduquesa Leopoldina na viagem que a uniria a seu marido, o príncipe dom Pedro de Alcântara (Freitas, 2017).

Ao analisar as febres no Rio de Janeiro, surpreendeu-se com a ausência do tipo contagioso, muito comum na Europa, segundo afirma, sendo mais frequentes as exantemáticas. $\mathrm{Na}$ abertura de seu ensaio, Mello Franco definia-se como médico experiente no assunto das febres, pois contava com "uma prática sem desvio, e sem interrupção na soberba e populosa Cidade de Lisboa" ao longo de 34 anos, o que o teria permitido criar seu próprio "sistema" de medicina. Além disso, também havia participado da comissão da Academia de Ciências de Lisboa que atuou no combate ao surto de febre epidêmica contagiosa na capital portuguesa em em 1811 (Freitas, 2017). Para Mello Franco, o caso do Rio de Janeiro exigia estudo específico, pois nem os estados febris propostos pela literatura europeia da época seriam aplicáveis aqui. Em tese, o clima quente e úmido deveria favorecer as febres contagiosas, mas não era o que se verificava:

Mas como, havendo tantas causas combinadas para o desenvolvimento dos eflúvios contagiosos, ficam eles sem atividade? É com efeito mui difícil, por não dizer impossível, dar uma explicação, que satisfaça o espírito filosófico: por que, sendo-nos inteiramente desconhecida a natureza de tais eflúvios, e, em geral, de todos os diferentes 'vírus', e miasmas, que por diversos modos atacam a organização humana, não se pode exatamente dizer, quais são os grandes agentes da Natureza, que lhes dão, ou tiram a sua força, e energia (Franco, 1829, p.45).

No entanto, o médico não se conforma em deixar a questão sem resposta. Baseandose nos estudos de Tiberius Cavallo (1749-1809), William Henley (?-1779) e outros que se dedicaram à questão da eletricidade animal, afirma que a resposta para ausência de febres contagiosas no Rio de Janeiro estaria relacionada à interação da eletricidade corporal dos indivíduos com a atmosfera carregada de fluidos elétricos da cidade:

Portanto sendo a atmosfera desta Cidade tão elétrica (como está referido) é natural, que a organização humana seja continuamente (por assim dizer) saturada daquele fluido; o qual se modifica no cérebro, e se distribui por todo o sistema nervoso, formando provavelmente, o que os Antigos chamavam de pabulum vitae, sem conhecerem ainda a eletricidade (Franco, 1829, p.47).

Embora as conclusões pareçam altamente especulativas, o impacto da obra não parece ter sido desprezível. Pedro Nava (2004, p.52) menciona que o ensaio permaneceu como referência por cerca de cinquenta anos na Faculdade de Medicina, até ser preterido pela obra de Torres Homem em 1877.

Se Mello Franco investigou as febres no Rio de Janeiro a partir de sua experiência clínica em solo europeu, outros autores aqui chegaram com bagagens distintas, adquiridas em outros domínios imperiais. Nesse sentido, a circulação de saberes médicos entre a América Portuguesa e o continente africano parece ter desempenhado papel importante no estudo das manifestações febris. José Maria Bomtempo, professor da então recém-criada Escola de Anatomia e Cirurgia, chegou ao Brasil em 1808, após temporada de sete anos na África 
ocidental. Em 1814, seis anos depois de sua chegada, escreveu a "Memória sobre algumas enfermidades do Rio de Janeiro" (Bomtempo, 1925), na qual se mostrava cético quanto à opinião corrente na cidade de que as febres seriam "moléstias mui frequentes". Para ele, a maior parte dos casos tomados como "febre maligna" não passariam de variações inofensivas do fenômeno, caracterizadas como febres essenciais:

Se toda a enfermidade, a qual traz consigo frequência de pulso, merece o nome de febre; então a quase todas as moléstias se poderia dar o nome de febres: mas se a divisão, e arranjamento metódico é preciso ao Prático para firmar a sua carreira clínica, também veremos que febres propriamente ditas não são tão vulgares nesse País; todavia elas existem e até muito ordinariamente diferentes do que ordinariamente se conceituam (Bomtempo, 1825, p.18).

Outro personagem de destaque do período foi o italiano Luiz Vicente de Simoni. Chegado ao Rio de Janeiro em 1817, partiu dois anos depois para Moçambique a serviço da Coroa portuguesa, onde permaneceu até 1824 (Rodrigues, 2006; Wagner, 2012). Durante sua estadia na África, escreveu o Tratado médico sobre o clima e enfermidades de Moçambique (Simoni, 1821), no qual faz detalhada descrição da geografia, clima e população local, assim como das enfermidades mais comuns e as terapêuticas tradicionais frequentemente utilizadas. Ao final, dedicou um capítulo inteiro às febres, que dividiu em quatro partes: caráter geral das febres do país; distinção das espécies de febres observadas; sistema geral seguido no tratamento das febres; e, por fim, uma última parte na qual propunha modificações aos sistemas médicos conhecidos segundo as particularidades observadas em Moçambique.

Conforme confessa em seu tratado, chegou ao domínio português na África aterrorizado pela fama mortífera do lugar: "só o seu nome horroriza quem o ouve e muito mais quem se vê na previsão de se transferir, seja por objeto de tráfego seja para um definitivo estabelecimento" (Simoni, 1821, p.6). Essa atitude foi transformada ao longo de sua estadia, o que inclusive o motivou a escrever o tratado, destinado a tornar a adaptação de seus sucessores no cargo de físico-mor menos apreensiva. Contudo, uma vez de volta ao Rio de Janeiro no pós-independência, o médico genovês foi convocado por dom Pedro I para integrar a comissão responsável pelo combate a um surto de febre epidêmica nas vilas de Magé e Macacu, ocorrido entre 1828 e 1829 (Simoni, s.d.).

\section{Considerações finais}

Como temos acompanhado, a variedade é a marca primordial das experiências com as febres. Seja pelo emaranhado nosográfico dos relatos na imprensa e nas correspondências privadas, ou pela variedade de causalidades e terapias indicadas nas obras de medicina, é difícil estabelecer padrões de atuação claros. Mas, como indicamos, além dos contornos epistemológicos da medicina do período analisado, essa diversidade também se deve à plasticidade ontológica que as febres possuíam na época. Em parte, sua quase onipresença na vida social se explicava pelo fato de as definições de febre mais comuns naqueles tempos - apesar de suas divergências - serem frouxas o suficiente para abrigar uma larga parcela 
do conjunto de manifestações patológicas que atingiam a maior parte dos indivíduos ao longo da vida. Dito de outra forma, morria-se muito de febre justamente porque muitos dos sintomas mais comuns poderiam ser atribuídos de alguma maneira a um quadro febril. No entanto, isso não nos autoriza a imputar um caráter meramente especulativo aos diagnósticos estabelecidos, visto que, como a literatura tem destacado (Hamlin, 2014; Bynum, 1981), essas classificações tenderam a evoluir em conjunto com o próprio conhecimento médico e são recursos poderosos para se compreender as concepções de corpo, saúde e doença que não raro davam fundamento a políticas públicas de saúde. No entanto, resta investigar com mais profundidade como essa evolução se deu de modo específico no ambiente luso-brasileiro, uma vez que parte de nossa intelectualidade operou esforços para produzir conhecimentos úteis e originais para o combate às febres nos chamados "climas tórridos". Como já mostramos aqui, o caminho parece promissor e aponta na direção de uma flexibilização dos fluxos tradicionais de circulação de conhecimento dentro do próprio Império Português, mostrando que as experiências adquiridas pelos funcionários reais em diversos domínios da Coroa frequentemente tinham peso igual ou superior ao da literatura médica produzida no continente europeu.

\section{AGRADECIMENTOS}

Esta pesquisa contou com financiamento da Fundação Biblioteca Nacional e da Fundação de Amparo à Pesquisa do Estado do Rio de Janeiro (Faperj).

\section{NOTAS}

${ }^{1}$ No contexto latino-americano, autores como Mónica García (2017) têm criticado o uso de concepções contemporâneas da febre amarela na análise dos discursos oitocentistas sobre a doença.

${ }^{2}$ Odair Franco (1969, p.8), assim como parte da historiografia, aponta o relato de Rosa como sendo a primeira manifestação de febre amarela no Brasil. A informação, contudo, é duvidosa e necessita de maiores investigações; portanto, não a consideraremos no momento.

\section{REFERÊNCIAS}

A SAÚDE PÚBLICA...

A saúde pública no Rio de dom João. Rio de Janeiro: Senac. 2008.

AVISO.

Aviso. Gazeta do Rio de Janeiro n.9, p.4. 29 jan. 1814.

AZEREDO, José Pinto.

Ensaio sobre algumas enfermidades de Angola. Lisboa: Colibri. 2013.

BARREIROS, Bruno Paulo Fernandes.

Concepções do corpo no Portugal do século XVIII: sensibilidade, higiene e saúde pública. Tese (Doutorado em História, Filosofia e Patrimônio da Ciência e da Tecnologia) - Universidade Nova de Lisboa, Lisboa. 2014.
BENCHIMOL, Jaime.

Dos micróbios aos mosquitos: febre amarela e revolução pasteuriana no Brasil. Rio de Janeiro: Editora Fiocruz. 1999.

BOMTEMPO, José Maria.

Memória sobre algumas enfermidades do Rio de Janeiro. In: Bomtempo, José Maria. Trabalhos médicos oferecidos à majestade do senhor dom Pedro I. Rio de Janeiro: Tipografia Nacional. 1825.

BOXER, Charles.

O império marítimo português (1415-1825). São

Paulo: Companhia das Letras. 2002.

BUCHAN, William.

Medicina doméstica ou tratado de prevenir, e curar as enfermidades com o regimento, e medicamentos símplices. Tradução Manoel Henriques de Paiva. Lisboa: Oficina Morazziana. 1788. 
BYNUM, William.

Cullen and the study of fevers in Britain, 1760-

1820. In: Bynum, William; Nutton, Vivian

(Org.). Theories of fever from Antiquity to the

Enlightenment. London: Wellcome Institute. p.135-148. 1981.

CAGLE, Hugh.

Assembling the tropics: science and medicine in Portugal's Empire, 1450-1700. Cambridge: Cambridge University Press. 2018.

CHALHOUB, Sidney.

Cidade febril: cortiços e epidemias na corte imperial. São Paulo: Companhia das Letras. 2004.

CHAVES, Jozé Manoel.

Febriologia acomodada também para as pessoas curiosas... Coimbra: Real Oficina da Universidade. 1790.

COSTA, Camillo Alexandre de Azevedo e. Requerimento ao rei. ACL, CU, 089, Cx.17, D.1600 (Arquivo Histórico Ultramarino, Lisboa). 3 jun. 1817.

CRUZ, João Rodrigues da.

Carta a Florêncio Francisco dos Santos Franco informando sobre uma epidemia de febre em São João del Rei. Manuscritos, I-27, 22, 081 (Biblioteca Nacional, Rio de Janeiro). 26 out. 1816.

DUCHESNEAU, François.

La physiologie des Lumières: empirisme, modèles et théories. Paris: Classiques Garnier. 2012.

FILGUEIRAS, Carlos Alberto Lombardi. The mishaps of peripheral science: the life and work of Manoel Joaquim Henriques de Paiva, luso-brazilian chemist and physician of the late Eighteenth Century. Ambix, v.2 n.39, p.82. 1992.

FRANCO, Francisco de Mello.

Ensaio sobre as febres do Rio de Janeiro. Lisboa: Academia de Ciências. 1829.

FRANCO, Odair.

História da febre amarela no Brasil. Rio de Janeiro: Imprensa Nacional. 1969.

FREITAS, Ricardo Cabral.

Os sentidos e as ideias: trajetória e concepções médicas de Francisco de Mello Franco na ilustração luso-brasileira (1776-1823). Tese (Doutorado em História das Ciências e da Saúde) - Casa de Oswaldo Cruz/Fiocruz, Rio de Janeiro. 2017.

GARCÍA, Mónica.

Histories and narratives of yellow fever in Latin America In: Jackson, Mark (Ed.). The Routledge history of disease. New York: Routledge. p.221238. 2017.
GAZETA...

Gazeta do Rio de Janeiro, n.51, p.2. 28 jun. 1817.

GAZETA...

Gazeta do Rio de Janeiro, n.7, p.3-4. 22 jan. 1814.

GAZETA..

Gazeta do Rio de Janeiro, n.85, p.3-4. 23 out.

1813.

GAZETA...

Gazeta do Rio de Janeiro, n.44, p.4. 30 maio 1812.

GAZETA...

Gazeta do Rio de Janeiro, n.42, p.3-4. 25 maio 1811.

GAZETA...

Gazeta do Rio de Janeiro, n.10, p.1. 2 fev. 1811.

GAZETA...

Gazeta do Rio de Janeiro, n.85, p.2-4. 9 jul. 1809.

HAMLIN, Christopher.

More than hot: a short history of fever. Baltimore: Johns Hopkins University Press. 2014.

MARROCOS, Luiz Joaquim dos Santos. Cartas de Luiz Joaquim dos Santos Marrocos, escritas do Rio de Janeiro à sua família em Lisboa, de 1811 a 1821. Anais da Biblioteca Nacional do Rio de Janeiro, v.55. 1939.

MISCELÂNEA.

Miscelânea: Portugal. Correio Brasiliense, v.9, n.53, p.682-689. 1812.

MORÃO, Simão Pinheiro.

Queixas repetidas em ecos dos arrecifes de

Pernambuco. Lisboa: Junta de Investigações do Ultramar. 1692.

NAVA, Pedro.

Capítulos da história da medicina no Brasil. Londrina: Eduel. 2004.

PAIVA, Manoel Henriques de.

Da febre e da sua curação em geral, ou novo e seguro método de curar facilmente, por meio dos ácidos minerais, todas as espécies de febre. Bahia: Tipografia de Manoel Antonio da Silva. 1813.

QUINLAN, Sean.

The great nation in decline: sex, modernity and health crises in Revolutionary France (17501850). Hampshire: Ashgate. 2007.

REY, Roselyne.

Naissance et développement du vitalisme en France. Oxford: Oxford University; Voltaire Foundation. 2014.

RODRIGUES, Eugénia.

Alimentação, saúde e império: o físico-mor Luís Vicente de Simoni e a nutrição dos moçambicanos. Arquipélago-História, v.9-10, p.621-660. 2006. 
ROSA, João Ferreira da.

Tratado único da constituição pestilencial de Pernambuco. Lisboa: Oficina de Miguel Menescal. 1694.

RUSSEL-WOOD, Anthony John. O Império português. Lisboa: Clube do Autor. 2016.

SCHIEBINGER, Londa.

Secret cures of slaves: people and medicine in the eighteenth-century atlantic world. Stanford: Stanford University Press. 2017.

SILVA, Francisco Innocencio da.

Dicionário bibliográfico português. t.3. Lisboa: Imprensa Nacional. 1858.

SILVA, Maria Beatriz Nizza da. Cultura letrada e cultura oral no Rio de Janeiro dos vice-reis. São Paulo: Unesp. 2013.

SIMONI, Luís Vicente de.

Tratado médico sobre o clima e enfermidades de Moçambique. Manuscritos, I-47, 23, 017; p.6 (Biblioteca Nacional, Rio de Janeiro). 1821.
SIMONI, Luís Vicente de.

Dicionário histórico-biográfico das ciências da saúde no Brasil (1832-1930). Verbete. Rio de Janeiro: Casa de Oswaldo Cruz/Fiocruz. Disponível em: <http://www.dichistoriasaude.coc.fiocruz.br/ iah/pt/verbetes/simonil.htm>. Acesso em: $3 \mathrm{dez}$. 2018. s.d.

TISSOT, Samuel Auguste.

Aviso ao povo acerca da sua saúde. Tradução Manoel Henriques de Paiva. Lisboa: Oficina de Filipe da Silva e Azevedo. 1786.

VILLALTA, Luiz Carlos.

O Brasil e a crise do Antigo Regime português, 17881822. Rio de Janeiro: Editora FGV. 2016.

WAGNER, Ana Paula.

Um olhar sobre algumas práticas de cura no Oitocentos. Tempo, Espaço, Linguagem, v.3, n.3, p.50-68. 2012.

WILLIAMS, Elizabeth A.

The physical and the moral: anthropology, physiology, and philosophical medicine in France, 1750-1850. Cambridge: Cambridge University Press. 1994. 